\title{
CHARACTERIZATION AND ANTIBIOGRAM STUDY OF CLOSTRIDIUM CHAUVOEI ISOLATED FROM FIELD CASES OF BLACK LEG IN CATTLE
}

\author{
M. S. Jowel, M. S. R. Khan, M. S. Parvej, M. Y. Ali, M. S. Ara, K. H. M. N. H. Nazir, M. F. R. Khan, M. \\ Rahman, M. T. Rahman and M. B. Rahman*
}

Department of Microbiology and Hygiene, Bangladesh Agricultural University, Mymensingh-2202, Bangladesh

\begin{abstract}
Clostridium chauvoei is the etiological agent of black quarter (BQ), an infectious disease affecting mainly young cattle and sheep. The present study was designed with a view to isolate and identifies $\mathrm{Cl}$. chauvoei from field cases. A total of 4 clinically suspected samples were collected during the period from January 2013 to November 2013 from Monohardi, Narshindi ( $\mathrm{n}=1)$; Sujanagar, Pabna $(\mathrm{n}=1)$ and Veterinary Clinic of Bangladesh Agricultural University, Mymensingh $(\mathrm{n}=2)$. The samples were processed and were cultured anaerobically on blood agar. Gram stain and hanging drop techniques were performed with the cultured bacteria. Biochemical properties of the isolates were studied, and antibiotic sensitivity test was done by disk diffusion method. In Gram stain, all isolates showed numerous short, thick, straight, round-ended, gram positive rod occurs singly or in short chains. The spores of the organism were elongated, oval, sub terminal or terminal and wider than the cell, giving a typical pear-shaped appearance. All the $\mathrm{Cl}$. chauvoei isolates fermented dextrose, maltose, lactose and sucrose and produced acid and gas. In case of mannitol fermentation, only acid was produced. Catalase, oxidase, methyl red, Voges-Proskauer and indole tests were found to be negative. All isolates were resistant to oxytetracycline, amoxicillin and ciprofloxacin, whereas the isolates were sensitive to penicillin and gentamicin. In conclusion, penicillin and gentamicin can be the drugs of choice for effective treatment of BQ in cattle of Bangladesh.
\end{abstract}

Keywords: Clostridium chauvoei, black quarter, cattle, penicillin

\section{INTRODUCTION}

Clostridium chauvoei is the causal agent of blackleg/black quarter in cattle, sheep, goats and other ruminant species (Radostits et al., 2006; Quinn et al., 2004). This is a spore forming bacteria. The spores remaining in pasture fields for decades are ingested by the host animal and reach the muscular tissue through the blood stream. These spores remain latent for years in the muscles and local hypoxia in tissues allows the spores to germinate and multiply, producing several lethal toxins (Radostits et al., 2006). The alpha toxin is more fatal and one of the major toxins involved in the pathogenicity of the disease (Useh et al., 2003; Hang'ombe et al., 2006). This toxin is reported ashemolytic, necrotic and histotoxic effects on host cell (Quinn et al., 2004). The high level of calcium chloride in host animal species not only activates the spores but also helps in germination of spores by damaging the local tissues and thereby producing anaerobiasis (Princewill, 1965).

The excavation of soil in pasture field by different environmental and mechanical factors also spread and activates the latent spores which lead to major outbreaks of black quarter in grazing animals (Collier et al., 1998). Infection is achieved by ingestion of the grass mixed with contaminated soil or through accidental and incidental wounds like castration, shearing etc.

This disease is characterized by the appearance of crepitating sounds with fluctuating swelling of one of the quarters, followed by rapid death (Naz et al., 2005). In endemic areas $\mathrm{Cl}$. chauvoei may be present in soil and feces (Hang'ombe et al., 2000). Once pasture has become heavily contaminated, cases of the disease usually occur year after year in susceptible animals (Quinn et al., 1994). In cattle, blackleg appears to be a non-traumatic, endogenous infection. Since infection of muscle tissue occurs in the absence of a wound or a break in the skin (Sippel, 1982) and a considerable proportion of bovines may harbor $\mathrm{Cl}$. chauvoei in their liver. Affected animals are depressed, febrile and lame (one side limb), presenting a hot, painful swelling that becomes cold, edematous with crepitating sound. Death is seen within 12 to 48 hours. This agent seems to have a preference for big muscles (thigh, diaphragm and heart), which at necropsy are dark red, dry and spongy (Sippel, 1982). Young growing ruminants on pasture are especially sensitive to $\mathrm{Cl}$. chauvoei in soil may be a significant factor, since the

*Corresponding e-mail address: bahanurr@gmail.com

Copyright $@ 2016$ Bangladesh Society for Veterinary Medicine

All rights reserved 0352/2016 


\section{S. Jowel and others}

disease occurs year after year on the same premises, usually in well-fed cattle less than 3 years old. The disease is prevalent in developing countries including Bangladesh and in all the states of India it is sporadic in nature, most cases of black quarter occur in the warm months of the year and death was observed in $73 \%$ BQ cases of cattle in Bangladesh (Sultana et al., 2008) but research works and field study on the present nature of black quarter is very scanty in Bangladesh. Presumptive diagnosis of blackleg is performed in the field cases of disease by clinical and pathological findings (Sultana et al., 2008); confirmatory diagnosis is performed by the identification of the microorganism by conventional microbiological characterization methods (Vannelli and Uzal, 1996) and molecular assay. The current study was carried out to isolate the organism from suspected cases of black quarter by conventional methods and also identify and selection of specific drug to treat black leg in cattle.

\section{MATERIALS AND METHODS}

\section{Sample collection}

A total of four clinically suspected samples (blood from affected site) were collected from Monohardi, Narshindi $(n=1)$; Sujanagar, Pabna $(n=1)$ and Veterinary Clinic of Bangladesh Agricultural University, Mymensingh $(n=2)$. Blood from the affected site (Figure 1) with serosanguineous fluid were collected by sterile syringe and carried in cool box to the Bacteriology Laboratory of the Department of Microbiology and Hygiene, Bangladesh Agricultural University (BAU).

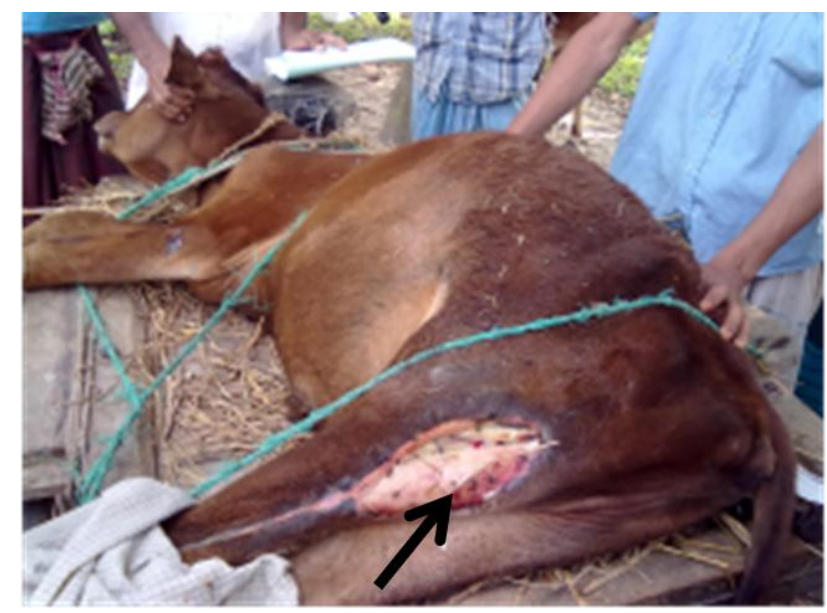

Figure 1. A calf affected with black quarter showing lesions (black arrow) due to black quarter

\section{Bacteriological analysis}

Collected serosanguineous fluid with blood was transferred to meat chop broth with mineral oil in anaerobic condition and kept in anaerobic candle jar, Incubated at $37^{\circ} \mathrm{C}$ for $36-48$ hours. After growth, the bacteria were inoculated on to Blood agar (Hi media, India) and incubated at $37^{\circ} \mathrm{C}$ for $36-48$ hours in anaerobic jar (Quinn et al., 2004). Bacteria showed white raised colony. Gram's staining and spore staining were performed to observe microscopic characteristics of bacteria as described by Pires et al. (2012). Morphological characteristics and biochemical tests were also performed from the culture as described by Pires et al. (2012). The carbohydrate fermentation test was performed by inoculating a loop full of bacterial culture into the individual tubes containing sugars like dextrose, maltose, lactose, sucrose, mannitol and incubated at $37^{\circ} \mathrm{C}$ for 48 hours. Acid production was indicated by the change of media from pink to yellow color while gas production was indicated by the appearance of gas bubbles in the inverted Durham's tubes. Methyl-Red (MR) test was performed by inoculating a colony of the test organism in $0.5 \mathrm{ml}$ sterile glucose phosphate broth. After overnight incubation at $37^{0} \mathrm{C}$, a drop of methyl red solution was added. A positive methyl red test was shown by the appearance of bright red colour indicated acidity while a yellow or orange colour was considered as negative. To perform Voges- 
Proskauer (VP) test five $\mathrm{ml}$ of sterile glucose phosphate peptone broth were inoculated with a pure colony of test organisms and incubated at $37^{\circ} \mathrm{C}$ for 24 hours. A very small amount (knife point) of creatine was added and mixed and $3 \mathrm{ml}$ of sodium hydroxide were added and shacked well. The bottle cap was removed and left for an hour at room temperature. It was observed closely for the slow development of a pink colour for positive cases. To perform Indole test two $\mathrm{ml}$ of peptone broth was inoculated with a pure colony of bacterial culture under observation and incubated at $37^{\circ} \mathrm{C}$ for 24 hours after which $0.5 \mathrm{ml}$ Kovac's reagent was added and shaked well and examined after 1 minute. A red colour in the reagent indicated positive test. The motility test was performed to differentiate motile bacteria from non-motile one. This test was performed in Hanging drop slide. One drop of distilled water was taken in the glass slide and with bacteriological loop a single colony was taken from the Blood agar, mixed it very well. Then it was observed under the microscope after cover slip was added.

\section{Antibiogram profile of the organisms}

Antibiotic sensitivity test of isolated bacteria was performed with standardized commercial antibiotic discs (Oxoid, UK) following Disc Diffusion Method (Bauer et al., 1966). Sensitivity to antibiotic was studied on Muller Hinton agar plates (Himedia, India) by disc diffusion method according to CLSI (2007). The antibiotic discs impregnated with ciprofloxacin $(5 \mathrm{mcg})$, penicillin $(10 \mathrm{mcg})$, gentamicin $(10 \mathrm{mcg})$ and oxytetracycline (30 $\mathrm{mcg})$, amoxicillin $(10 \mathrm{mcg})$, neomycin $(10 \mathrm{mcg})$ were used in this study. Isolated colonies of the same morphological type are selected from agar plate culture. The top of the colony is touched with a loop and the growth is transferred into a tube containing $4-5 \mathrm{~mL}$ of a suitable broth. The broth culture is incubated at $37^{\circ} \mathrm{C}$ for overnight. The growth of bacteria was observed and the turbidity was compared to Mecferland standard 0.5. $M$.

Sterile cotton swab is dipped into the broth suspension. The swab should be rotated several times and pressed firmly on the inside wall of the tube above the fluid level. This will remove excess inoculums from the swab.

The dried surface of a Mueller-Hinton agar plate is inoculated by streaking the swab over the entire sterile agar surface. This procedure is repeated by streaking two more times, rotating the plate approximately 6 each time to ensure an even distribution of inoculums. As a final step, the rim of the agar is swabbed. The plate was kept for 3 to 5 minutes, to allow for any excess surface moisture to be absorbed before applying the drug impregnated disks. The predetermined battery of antimicrobial discs is dispensed onto the surface of the inoculated agar plate. Each disc must be pressed down to ensure complete contact with the agar surface. Whether the discs are placed down individually or with a dispensing apparatus, they must be distributed evenly so that they are no closer than $24 \mathrm{~mm}$ from centre to centre. The plates are inverted and placed in an incubator set to $37^{\circ} \mathrm{C}$ within 15 minutes after the disc are applied. After 16 to 18 hours of incubation each plate is examined. If the plate was satisfactorily streaked, and the inoculum was correct, the resulting zones of inhibition will be uniformly circular and there will be a confluent lawn of growth. If individual colonies are apparent, the inoculum was too light and the test must be repeated. The diameters of the inhibition zones are measured to the nearest whole millimeter, using sliding calipers or a ruler, which is held on the back of the inverted petri plate. The petri plate is held a few inches above a nonreflecting background and illuminated with reflected light. The results were recorded at 16-18 hours post incubation. Transmitted light is used to examine the zone of inhibition. The zone margin should be taken as the area showing no obvious, visible growth that can be detected with the unaided eye. Faint growth of tiny colonies, which can be detected only with a magnifying lens at the edge of the zone of inhibited growth, is ignored. The sizes of the zones of inhibition are interpreted according to Zone of Diameter Interpretative Standards of CLSI (2007).

\section{RESULTS AND DISCUSSION}

Black quarter is considered one of the most fatal diseases of livestock with significant economic impact globally (Quinn et al., 2004; Radostits et al., 2006). The Cl. chauvoei is a strict anaerobe microorganism and it survives in the environment and in host muscles for decades and $\mathrm{Cl}$. chauvoei can infect animals grazing on contaminated pastures leaving a need to establish diagnostic facilities at local settings for efficient monitoring of the disease. To the end of this investigations made during this study indicated that the microorganism was numerous short, thick, straight, round-ended, gram positive rod occurs singly or in short chains (figure 2). The spores of the organism were elongated, oval, sub terminal or terminal and wider than the cell, giving a typical pear-shaped appearance. In blood agar, the round colonies were tentatively identified as Clostridium spp. which were used for sub culture. In the pure culture, the colonies were small, irregular, whitish pale colored, finely 


\section{S. Jowel and others}

granular in the center but almost invisible toward the periphery. The edges of the colony resemble wisps of hair and surrounded by a typical zone of hemolysis which resembled to the colony characteristics of $\mathrm{Cl}$. chauvoei (figure 3). All isolates fermented dextrose, lactose, sucrose, maltose and produced acid and gas but did not ferment mannitol. All suspected samples were catalase and oxidase negative, were Indole, VP and MR negative and these properties of the organisms were typical to $\mathrm{Cl}$. Chauvoei (Moosawai et al., 1999; Naz et al., 2005 and Bagge et al., 2009). So, all were finally identified as Clostridium chauvoei. The isolated organisms were sensitive to penicillin and gentamycin, intermediate sensitive to neomycin while resistant to oxytetracycline, amoxicillin and ciprofloxacin (figure 4). Inam-ul-Haq and Niamatullah (2011) found efficiency of treatment trials as two broad spectrum antibiotics e.g. Amoxicillin and Oxytetracycline against black leg under field conditions. The isolated organisms showed resistant to Oxytetracycline, it may be due to frequent use of these antibiotics without maintaining proper dose. In our study, all isolates (100\%) were sensitive to penicillin and gentamicin.

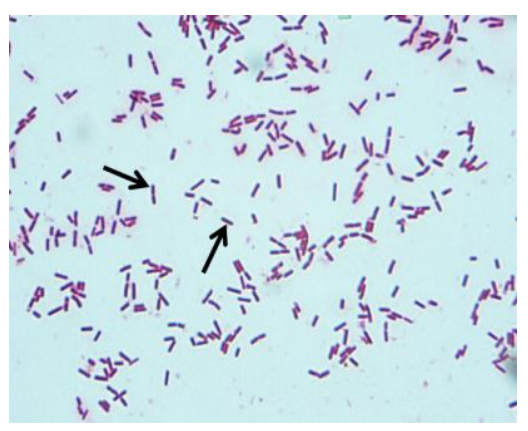

Figure 2. Gram's staining of Clostridium chauvoei showing Gram positive, short, thick, straight, roundended rod (black arrows).

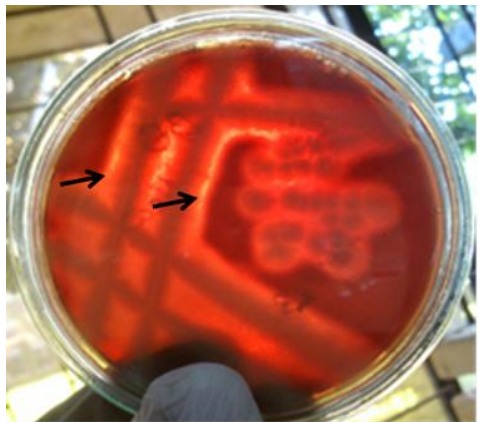

Figure 3. Characteristics hemolysis (black arrows) of Clostridium chauvoei on blood agar

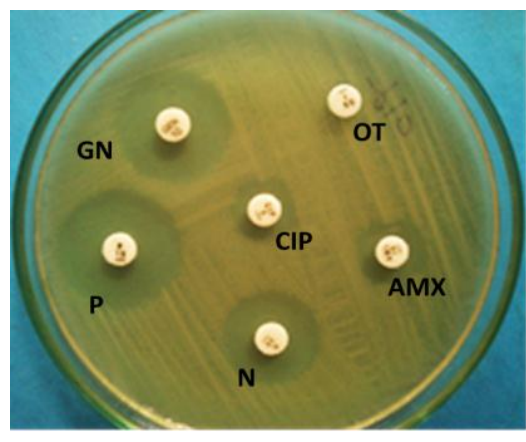

Figure 4. Antibiogram of Clostridium chauvoei against six commonly used antibiotics. $\mathrm{GE}=$ Gentamicin, $\mathrm{P}=$ Penicillin, $\mathrm{N}=$ Neomycin, $\mathrm{CIP}=$ Ciprofloxacin, OT = Oxytetracycline, AMX = Amoxicillin

\section{CONCLUSION}

Findings of this study indicate that $\mathrm{Cl}$. chauvoei is prevalent in cattle throughout the study area of Bangladesh. Moreover, the conventional culture and biochemical tests were effective method than clinical manifestation and pathological findings when compared to for the diagnosis of BQ. Penicillin and gentamicin are the drug of choice in the treatment of black leg in Bangladesh. These findings provide baseline to perform country wide epidemiological studies, effective vaccine programs and design strategies for eradication of the disease from the country with ultimate goal to minimize economic loss in livestock sector due to black leg in ruminant animals each year in Bangladesh.

\section{REFERENCES}

1. Bagge E, Lewerin SS and Johansson KE (2009). Detection and identification by PCR of Clostridium chauvoei in clinical isolates, bovine tuberculosis complex organisms. Journal of Veterinary Diagnostics and Investigation 9: 244-249.

2. Bauer AW, Kirby WMM, Sheris JC and Truck M (1966). Antibiotic susceptibility testing by a standardized single disc method. American Journal of Clinical Pathology 45: 493-496

3. CLSI (2007). Performance standards for antimicrobial susceptibility testing. $17^{\text {th }}$ informational supplement document M100-S17:1. Wayne, Pennsylvania. pp. 32-50.

4. Collier L, Balows A and Sussman M (1998). Topley and Wilson's Microbiology and Microbial infections. $9^{\text {th }}$ Ed., Arnold, London, UK.

5. Hang'ombe BM, Isogai E, Lungu J, Mubita C, Nambota A, Kirisawa R, Kimura K and Isogai H (2000). Detection and characterization of Clostridium species in soil of Zambia. Comparative Immunology, Microbiology and Infectious Diseases 23: 277-284. 


\section{S. Jowel and others}

6. Hang'ombe BM, Kohda T, Mukamoto M and Kozaki S (2006). Purification and sensitivity of Clostridium chauvoei hemolysin to various erythrocytes. Comparative Immunology, Microbiology and Infectious Diseases 29: 263-268.

7. Inam-ul-Haq AA and Niamatullah M (2011). Economic losses due to high incidence of Black quarter disease in cattle and buffaloes and its treatment in district Dera Ismail Khan. Pakistan Journal of Science 63: 115-117

8. Moosawi M, Ardehali M, Farzan A and Pilehchian P (1999). Isolation and identification of Clostridium strains from cattle malignant edema cases. Archives of Razi Institute 50

9. Naz S, Ahmad S and Bhatt JI (2005). Isolation and identification of Clostridium chauvoei from cattle and buffaloes, Pakistan Veterinary Journal 25: 101-102.

10. Pires PS, Ecco R, de Araújo MR, Silva ROS, Salvarani FM, Heneine LGD, Assis RA and Lobato FCF (2012). Comparative analysis of lesions caused by histotoxic clostridia in experimentally induced myonecrosis,Semina: Ciências Agrárias 33: 337-2346.

11. Princewill TJT (1965). Effect of calcium chloride on germination and pathogenicity of Clostridium chauvoei. Journal of Comparative Pathology 75: 343- 351.

12. Quinn PJ, Carter ME, Markey B and Carter GR (1994). Clostridium species, Clinical Veterinary Microbiology. London, UK, pp. 191-208.

13. Quinn PJ, Carter ME, Markey B and Carter GR (2004). Clinical Veterinary Microbiology. $2^{\text {nd }}$ Ed: Elsevier - Health Sciences Division. USA, pp. 191-208

14. Radostits OM, Gay CC, Hinchcliff KW and Constable PD (2006). Diseases associated with Clostridium species in Veterinary Medicine. $10^{\text {th }}$ ed. WB Saunders Company Ltd. London. pp. 828-830.

15. Sippel WL (1982). Diagnosis of clostridial diseases. Journal of the American Veterinary Medical Association 161: 1299-1305.

16. Sultana M, Ahad A, Biswas PK, Rahman MA and Barua H (2008). Black quarter (BQ) disease in cattle and diagnosis of bq septicaemia based on gross lesions and microscopic examination. Bangladesh Journal of Microbiology 25: 13-16

17. Useh NM, Nok AJ and Esievo KA (2003). Pathogenesis and pathology of blackleg in ruminants: the role of toxins and neuraminidase. A short review. The Veterinary Quarterly 25: 155-159.

18. Vannelli SA and Uzal FA (1996). Identification of Clostridium sordellii by a peroxidase antiperoxidase (PAP) technique in smears and informalin-fixed, paraffin-embedded tissues of sheep. Revue de Médecine Vétérinaire 77: 306-312. 